\title{
RANCANG BANGUN KONTROL PENYUSUNAN KEMBALI SUSUNAN MODUL PHOTOVOLTAIK (PV) UNTUK APLIKASI POMPA AIR VOLUMETRIK
}

\author{
Aceng Daud \\ Teknik Konversi Energi- Politeknik Negeri Bandung \\ E-mail: daud_polban@yahoo.com
}

\begin{abstract}
Abstrak
Makalah ini menampilkan suatu teknik untuk meningkatkan kinerja modul photovoltaik (PV) yang mensuplai motor DC magnet permanen yang dikopel pada sebuah pompa air volumetrik. Metoda ini menggunakan sebuah kontrol penyusunan kembali susunan modul photovoltaik $(P V)$ menggunakan saklar solid state, yang menyensor radiasi rendah, menengah, dan tinggi. Pengontrol memilih salah satu set karakteristik $I-V$ untuk starting dan karakteristik I-V yang lain untuk keadaan mantap. Ini dilakukan dengan pensaklaran panelpanel surya yang bergantung pada arus starting yang dibutuhkan dan tingkat radiasi, untuk hubungan paralel, seri-paralel, dan seri. Prosedur ini mencukupi arus mula, khususnya pada radiasi rendah dan menengah, yang akan meningkatkan kinerja pompa, terutama sekali pada pagi, sore dan hari-hari berawan.
\end{abstract}

Kata kunci:photovoltaik, motor DC, pompa air volumetrik

\section{PENDAHULUAN}

Penggunaan modul-modul photovoltaik (PV) untuk mensuplai sistem pompa air semakin banyak akibat semakin menurunnya biaya panel-panel solar, walupun efisiensi panel solar masih relatif rendah. Ini menarik untuk menggunakan alat yang sederhana dan murah yang akan menaikan kinerja suatu modul photovoltaik yang mensuplai pompa air. Teknik-teknik telah banyak dicoba untuk meningkatkan kinerja pompa air photovoltaik. Telenik-teknik tersebut termasuk "optimal matching" dari sistem yang dikopel langsung, sumbu tunggal (single-axis) dan sumbu ganda (double-axis) penjejak matahari, dan penjejak titik daya maksimum (maximum power point tracker).

Sebuah pompa air volumetrik yang dikopel langsung dengan sebuah motor DC magnet permanen diketahui mempunyai torsi mula (starting) yang konstan yang bergantung hanya kepada tinggi (h), dan debit air (Q), tapi tidak bergantung pada kecepatan (n). Untuk menanggulangi torsi mula, suatu tingkat radiasi yang cukup tinggi (kira-kira $600 \mathrm{~W} / \mathrm{m}^{2}$ ) harus tersedia. Oleh karena itu, untuk mengoperasikan tipe pompa ini pada tingkat radiasi rendah dan menengah, torsi yang dikembangkan oleh motor harus naik. Kenaikan torsi pada motor tentunya akan menaikan arus pada motor atau sebaliknya. Suatu cara yang logis untuk mencapai hal tersebut yaitu dengan penyusunan kembali susunan photovoltaik modulama radiasi rendah dan menengah.

Dalam makalah ini susunan photovoltaik dikelompokan dalam empat unit. Keempat unit ini dihubungkan paralel modulama tingkat radiasi rendah, seri-paralel modulama tingkat radiasi menengah, dan dihubungkan seri modulama tingkat radiasi tinggi. Pengontrolan dilakukan dengan kontrol penyusunan kembali modul potovoltaik (PV) tiga tingkat.

\section{DASAR TEORI}

Suatu motor DC magnet permanen dapat digambarkan dengan sebuah sumber tegangan, $\left(V_{t}\right)$ yang seri dengan tahanan jangkar $\left(R_{a}\right)$ dan tegangan yang diinduksikan (E). Persamaan dari motor magnet permanen adalah sebagai berikut :

$$
\begin{aligned}
& V_{t}=E+I_{a} \cdot R_{a} \\
& E=K \cdot \phi \cdot \omega_{m} \\
& T_{m}=K \cdot \phi \cdot I_{a}
\end{aligned}
$$

dimana: 
$\mathrm{V}_{\mathrm{t}}=$ tegangan terminal motor $(\mathrm{V})$

$\mathrm{E}=$ tegangan nduksi motor $(\mathrm{V})$

$\mathrm{Ra}=$ tahanan jangkar $(\Omega)$

$\phi=$ fluksi (weber)

$\omega_{\mathrm{m}}=$ kecepatan sudut motor (rad/detik)

$\mathrm{T}_{\mathrm{m}}=$ torsi motor $\left(\mathrm{N}_{\mathrm{m}}\right)$

Perbandingan daya yang dipakai oleh motor dan daya yang digunakan oleh pompa untuk mengangkat air pada suatu ketinggian (h) tertentu, diketahui sebagai efisiensi $(\eta)$ kawat ke air yang dinyatakan dengan :

$$
\eta=\rho \cdot g \cdot h \cdot Q / P_{i}
$$

dengan :

$$
P_{i}=V_{t} \cdot I_{a}
$$

dimana:

$$
\begin{aligned}
& \rho=\text { grafitas sfesifik air } \quad\left(\mathrm{kg} / \mathrm{m}^{3}\right) \\
& \mathrm{g}=\text { grafitasi }\left(\mathrm{m} / \text { detik }^{2}\right) \\
& \mathrm{h}=\text { tinggi }(\mathrm{m}) \\
& Q=\text { aliran air }\left(\mathrm{m}^{3} / \text { detik }\right) \\
& \mathrm{P}_{1}=\text { daya masukan motor }(\mathrm{W})
\end{aligned}
$$

Dari data-data pembuat pompa, kecepatan motor, $\omega_{\mathrm{m}}$ dan efisiensi, $\eta$ dapat dicari untuk berbagai tinggi, $\mathrm{h}$ yang berbeda, dan dengan menggunakan Persamaan (1) sampai dengan (5), arus jangkar dapat ditentukan, sehingga kurva $\mathrm{I}-\mathrm{V}$ dari sistem dapat diperoleh.

Daya keluaran dari modul photovoltaik adalah hasil dari tegangan keluaran dan arus keluaran modul. Rangkaian ekivalen dari sebuah panel photovoltaik diperlihatkan pada Gambar 1.

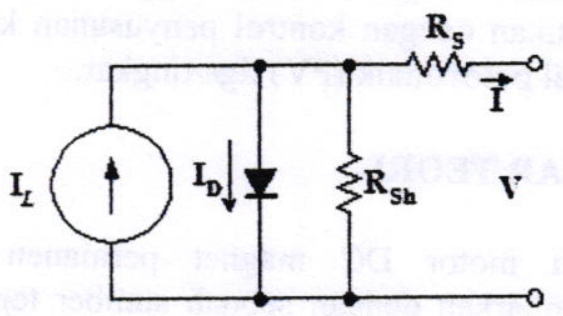

Gambar I Rangkaian ekivalen modul potovoltaik (PV)

Persamaan yang menghubungkan arus susuhan photovoltaik (PV) dengan tegangan susunan photovoltaik (PV) adalah ${ }^{[1]}$ :

$$
I=I_{S C}\left\{1-C_{3}\left[e^{\left(C_{4} \cdot V^{\mathrm{m}}\right)}-1\right]\right\}
$$

dengan :

$$
\begin{aligned}
& \mathrm{C}_{3}=0,01175 \\
& \mathrm{C}_{4}=\mathrm{C}_{6} / \mathrm{V}_{\mathrm{OC}} \\
& \mathrm{C}_{6}=\ln \left[\left(1+\mathrm{C}_{3}\right) / \mathrm{C}_{3}\right] \\
& \mathrm{C}_{5}=\ln \left\{\frac{\mathrm{I}_{\mathrm{SC}}\left(1+\mathrm{C}_{3}\right)-\mathrm{I}_{\mathrm{mp}}}{\mathrm{C}_{3} \mathrm{I}_{\mathrm{SC}}}\right\}
\end{aligned}
$$

Persamaan (6) menjelaskan kurva I-V hanya pada satu tingkat radiasi dan temperatur. Untuk membuat Persamaan tersebut (6) berlaku untuk radiasi dan temperatur yang lain, kurva dirubah ke persamaan (7), yaitu :

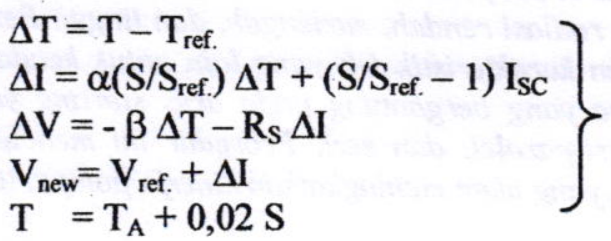

dimana:

$\alpha \quad=$ koefisien temp. perubahan arus pd.

radiasi acuan $\left(\mathrm{amp} . /^{\circ} \mathrm{C}\right)$

$\beta \quad=$ koefisien temp. perubahan tegangan $\mathrm{pd}$.

Radiasi acuan $\left(\mathrm{V} /{ }^{\circ} \mathrm{C}\right)$

I $=\operatorname{arus} \operatorname{modul}(\mathrm{A})$

$\mathrm{I}_{\mathrm{mp}} \quad=$ arus daya maksimum modul (A)

ISC = arus hubung singkat modul (A)

$\mathrm{S} \quad=$ radiasi Tilt total $\left(\mathrm{W} / \mathrm{m}^{2}\right)$

$\mathrm{S}_{\text {ref }} \quad=$ radiasi acuan $\left(\mathrm{W} / \mathrm{m}^{2}\right)$

$\mathrm{R}_{\mathrm{S}} \quad=$ Tahanan seri $\operatorname{modul}(\Omega)$

$\mathrm{T} \quad=$ temperatur $\left({ }^{\circ} \mathrm{C}\right)$

$\mathrm{T}_{\mathrm{A}} \quad=$ temperatur lingkungan $\left({ }^{\circ} \mathrm{C}\right)$

$\mathrm{T}_{\text {ref. }} \quad=$ temperatur acuan $\left({ }^{\circ} \mathrm{C}\right)$

$\Delta \mathrm{T} \quad=$ perubahan temperatur $\left({ }^{\circ} \mathrm{C}\right)$

$\mathrm{V} \quad=$ tegangan modul (V)

$\mathrm{V}_{\mathrm{mp}} \quad=$ tegangan daya maksimum (V)

$\mathrm{V}_{\mathrm{OC}} \quad=$ tegangan hubungan terbuka $(\mathrm{V})$

$\mathrm{S} \quad=\operatorname{radiasi}\left(\mathrm{W} / \mathrm{m}^{2}\right)$

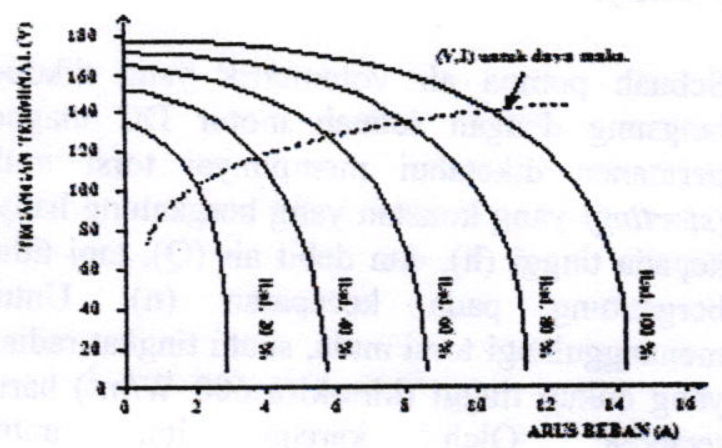

Gambar 2 Karaktrristik I-V photovoltaik tipikal 
Karakteristik tipikal dari hubungan arus dan tegangan susunan photovoltaik diperlihatkan pada Gambar 2.

Tahanan seri, $\mathbf{R}_{\mathbf{S}}$ dihitung dari percobaan karakteristik I-V pada dua tingkat radiasi yang berbeda. Dengan menggunakan persamaan diatas, karakteristik I-V susunan photovoltaik (PV) dapat dibuat dengan pertolongan komputer atau dengan metoda iterasi.

Gambar 3 memperlihatkan sebuah kurva I-V dari pompa-motor, dimana pompa pada suatu tekanan $100 \mathrm{psi}$; dan susunan photovoltaik (PV) dihubungkan dalam paralel, seri-paralel, dan seri.

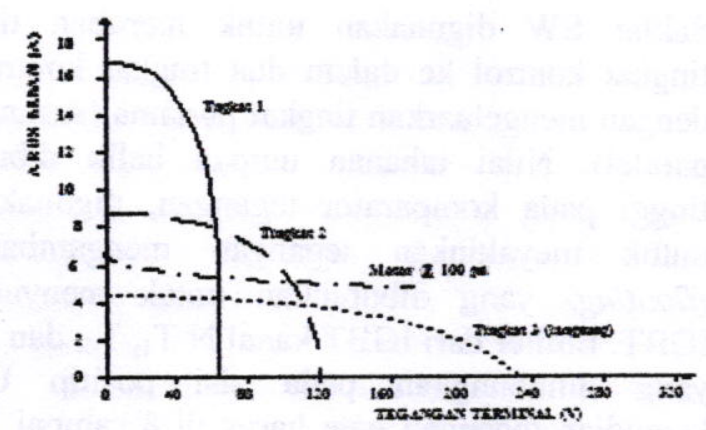

Gambar 3 Kurva I-V susunan photovoltsik dan pompa-motor pada tingkat radiasi $500 \mathrm{~W} / \mathrm{m}^{2}$

Dari Gambar 3, arus yang tersedia untuk motor pada beberapa tingkat, maksimum pada tingkat pertama (hubungan paralel), menengah pada tingkat kedua (hubungan seri-partalel), dan minimum pada tingkat ketiga (hubungan langsung). Titik starting dari sistem motorpompa terjadi pada perpotongan kurva I-V dari susunan modul potovoltaik (PV) dan kurva I-V dari motor-pompa.

\section{PERANCANGAN RANGKAIAN DAN OPERASI}

Perancangan kontrol daya tingkat dilakukan untuk mengelompokkan susunan photovoltaik (PV) dalam empat unit $U_{1}, U_{2}, U_{3}$, dan $U_{4}$. Setiap unit terdiri dari sejumlah modul yang tetap. Keempat unit ini diinterkoneksi melalui sembilan IGBT (insulated gate bipolar transistor) kanal N, seperti diperlihatkan dalam gambar 4. IGBT digunakan sebagai alat pensaklaran sebab kemampuan arusnya tinggi, tahanan dalam kecil, dan mudah untuk dikontrol.

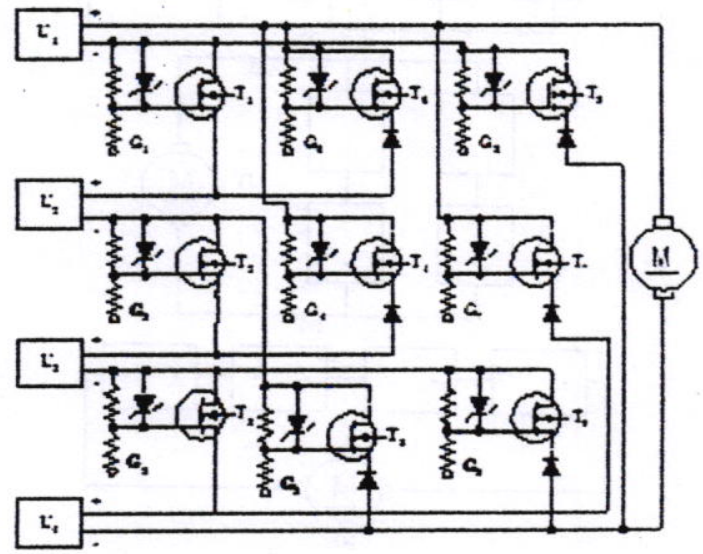

Gambar 4 Kontrol rangkaian daya tiga tingkat.

Pada tingkat radiasi rendah, keempat unit photopoltaik (PV) dihubungkan dalam paralel, sebagaimana diperlihatkan dalam gambar 5 (a), dengan menyulut $T_{4}, T_{5}, T_{6}, T_{7}, T_{8}$, dan $T_{9}$. Setiap unit menyediakan arus I dan tegangan $\mathrm{V}$, sehingga arus yang tersedia pada motor sebesar $4 \mathrm{I}$ dan tegangannya sebesar $\mathrm{V}$ yang menyediakan arus tinggi untuk starting.

Pada tingkat radiasi menengah, unit dikelompokan dalam dua set (setiap set terdiri dari dua unit yang dihubungkan seri). Dua set ini kemudian dihubungkan paralel untuk membentuk hubungan seri-paralel, sebagaimana diperlihatkan dalam gambar 5 (b) dengan menyulut $T_{1}, T_{3}, T_{4}$, dan $T_{5}$. Dalam kasusu ini arus yang tersedia pada motor sebesar 2I Dan tegangannya sebesar 2V.

Pada tingkat radiasi tinggi, keempat unit dihubungkan dalam seri, sebagaimana diperlihatkan dalam gambar 5 (c) dengan menyulut $T_{1}, T_{2}$, dan $T_{3}$. Dalam kasus ini arus yang tersedia pada motor sebesar I dan tegangannya sebesar $4 \mathrm{~V}$.

Karena motor DC magnet permanen dapat dioperasikan pada suatu daerah tegangan masukan yang lebar, maka suatu perubahan tegangan tidak akan mencegah motor untuk beroperasi. 


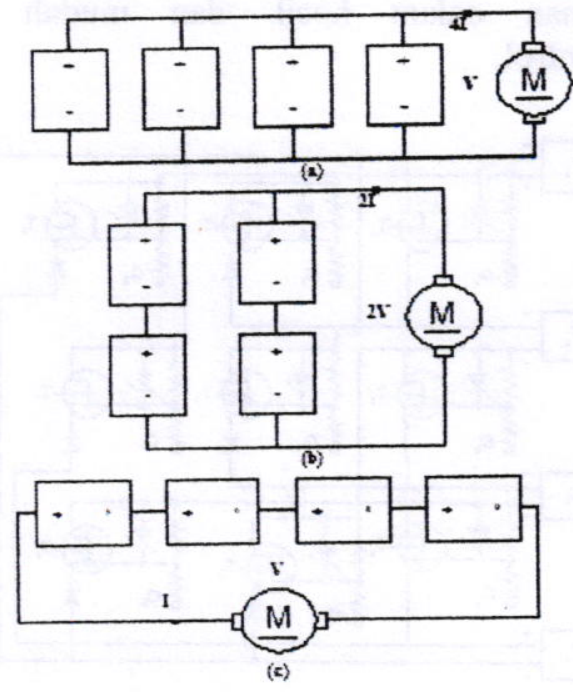

Gambar 5 Penyusuanan kembali susunan modul potovoltaik (PV). (a) Tingkat 1 untuk radiasi rendah,

(b) Tingkat 2 untuk radiasi menengah, dan (c) Tingkat 3 untuk radiasi tinggi.

Gambar 6 memperlihatkan rangkaian kontrol logika yang mengimplementasikan pensaklaran saklar-saklar IGBT untuk melalukan tiga langkah pensaklaran sesuai dengan tingkat radiasi yang dảang. Rangkaian kontrol logika mengontrol radiasi yang datang, yaitu rendah, menengah, dan tinggi dengan pertolongan sebuah modull solar acuan yang dibuat dari bahan yang sama sebagaimana modul-modul potovoltaik (PV). Modul dipasang pada bidang yang sama dan dalam arah yang sama sebagaimana susunan modul potovoltaik (PV). Modul potovoltaik akan menghasilkan arus sebanding dengan jumlah radiasi matahari yang datang. Arus ini dirubah dalam bentuk sinyal tegangan oleh hubungan resistor yang paralel dengan modul potovoltaik. Tegangan ini kemudian dimasukkan pada komparator tegangan rendah (L) dan komparator tegangan tinggi $(\mathrm{H})$. Komparator tegangan rendah $(\mathrm{L})$ bekerja bila radiasi yang datang lebih rendah dari set poin radiasi rendah. Komparator ini akan menghubungkan saklar IGBT $\mathrm{T}_{4}, \mathrm{~T}_{5}, \mathrm{~T}_{6}$, $T_{7}, T_{8}$, dan $T_{9}$ yang menghubungkan empat unit photovoltaik dalam paralel. Bila radiasi datang lebih tiinggi dari set poin radiasi tinggi, komparator tegangan tinggi $(\mathrm{H})$ akan bekerja yang menyebabkan $T_{1}, T_{2}$, dan $T_{3}$ menghubung sehingga menyambungkan keempat unit photovoltaik (PV) dalam hubungan seri. Set poin ini dapat divariasikan dengan mengatur potensiometer $\mathbf{R}_{1}$ dan $\mathbf{R}_{2}$. Komparator tegangan menengah $(\mathrm{M})$ bekerja bila radiasi yang datang berada antara set poin radiasi rendah (L) dan set poin radiasi tinggi $(\mathrm{H})$. Komparator tegangan menengah (M) bekerja sebab komparator tegangan rendah $(\mathrm{L})$ dan komparator tegangan tinggi $(\mathrm{H})$ tidak bekerja dan tegangan pada titik $\mathrm{C}$ sama dengan nol. Bila komparator tegangan menengah (M) bekerja, $T_{1}, T_{3}, T_{4}$, dan $T_{5}$ terhubung untuk menyediakan hubungan seriparalel. Bila salah satu komparator teganan rendah $(\mathrm{L})$ atau komparator tegangan tinggi $(\mathrm{H})$ bekerja, tegangan pada titik $\mathrm{C}$ tidak sama dengan nol, sehingga akan mencegah komparator tegangan menengah $(\mathrm{M})$ bekerja. Dioda $D_{1}$ dan $D_{2}$ digunakan untuk meyakinkan bahwa hanya satu tingkat saklar yang akan bekerja pada saat kapanpun.

Saklar SW digunakan untuk merubah tiga tingkat kontrol ke dalam dua tingkat kontrol, dengan mengeluarkan tingkat pertama (susunan paralel). Nilai tahanan umpan balik dibuat tinggi pada komparator tegangan, digunakan untuk meyakinkan tegangan mengambang (floating) yang dibutuhkan untuk menyulut IGBT. Emiter dari IGBT kanal N $T_{4}, T_{6}$, dan $T_{7}$ yang dihubungkan pada sisi positip $U_{1}$, kemudian tegangan gate harus di 8 sampai 12 volt lebih tinggi dari tegangan emiter agar IGBT bekerja. Oleh karenanya sumber tegangan terisolasi (SS) digunakan untuk menyediakan tegangan tersebut.

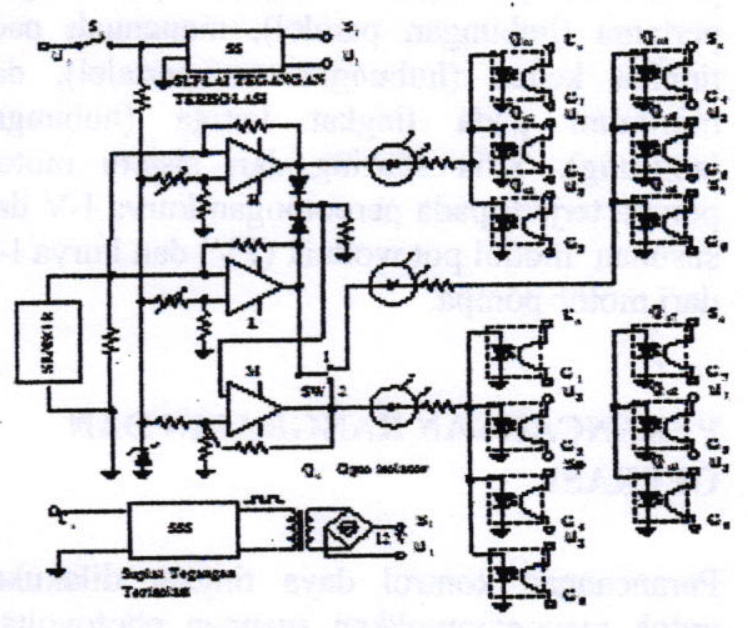

Gambar 6 Rangkaian kontrol tiga tingkat.

Bila mesin start dari keadaan diam, rangkaian kontrol akan mulai bekerja dari tingkat satu (susunan paralel) pindah ke tingkat dua (susunan seri-paralel) dan ke tingkat tiga (susunan seri), sesuai tingkat radiasi yang 
tersedia.

\section{HASIL DAN DISKUSI}

Suatu sistem loop tertutup, dimana air dipompa dari tangki melawan sebuah katup bertekanan dan kembali ke tangki telah dibuat dan diperlihatkan dalam Gambar 7. Tekanan yang menstimulasikan tinggi, dapat diubah dengan mengatur katup tekanan.

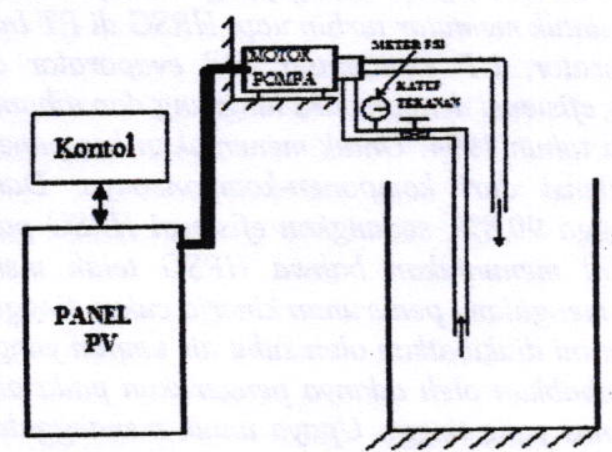

Gambar 7 Sistem photovoltaik (PV) yang mensuplai motor-pompa.

Sebuah pompa kapasitas 1,5 HP (1119 Watt), digerakan oleh sebuah motor DC magnet permanen 1,5 HP, 180 volt telah diuji. Radiasi pada saat pompa mulai memompa melawan tinggi 100 psi telah dicatat. Gambar 8 memperlihatkan tingkat radiasi yang dibutuhkan untuk menjalankan sistem dengan menggunakan pengontrol tiga tingkat.

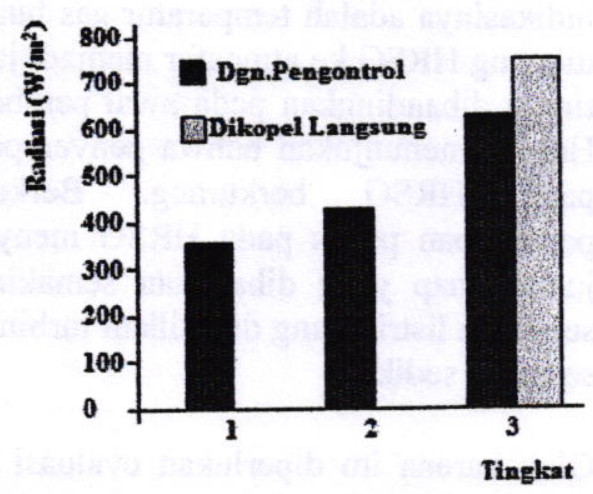

Gambar 8 Titik start untuk sistem operasi pengontrol pada 100 psi.

Rating aliran air dalam liter per menit sebagai fugsi dari tingkat radiasi diperlihatkan dalam Gambar 9 (a) dan (b) untuk takanan 100 psi. Gambar 9 (a) memperlihatkan rating aliran air untuk sistem bila dikopel langsung (tanpa kontrol), sementara Gambar 9 (b) memperlihatkan rating aliran air bila kontrol digunakan.

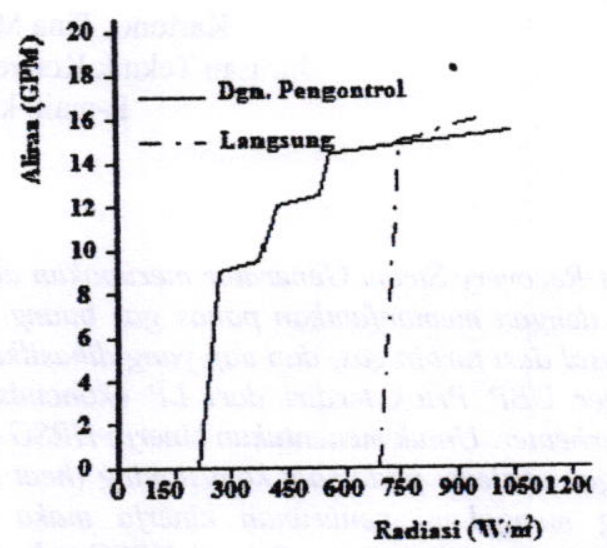

Gambar 9 Rating aliran sebagai fungsi radiasi dikopel langsung dan dengan pengontrol.

\section{KESIMPULAN}

Kontrol penyusunan kembali susunan modul potovoltaik (PV) memperkenalkan suatu pendekatan untuk mengoptimalkan pompa air volumetrik yang disuplai modul potovoltaik (PV) dengan menghasilkan arus yang cukup tinggi untuk menjalankan motor pada tingkat radiasi rendah, sehingga menyediakan suatu daerah tingkat radiasi yang lebar untuk operasi dan jam pemompaaan air.

\section{DAFTAR PUSTAKA}

Bogdan S. Borowy dan Ziyad M.Salameh, Sept. 1994"Optimum Photovoltaic Array Size For a Hybrid Wind/PV Sistem". IEEE TEC., Vol.9, No. 3.

Ryder, 1970. Electronic Fundamentals \& Applications. Pitman Publishing. 